09,03

\title{
Природа стимулированного излучения ZnO в широком температурном интервале
}

\author{
(ㄷ И.Х. Акопян, М.Э. Лабзовская ฯ, Б.В. Новиков, А.Ю. Серов \\ Санкт-Петербургский государственный университет, \\ Санкт-Петербург, Россия \\ ฯ E-mail: xrul@mail.ru
}

Поступила в Редакцию 25 июля 2021 г.

В окончательной редакции 25 июля 2021 г.

Принята к публикации 4 августа 2021 г.

Исследовано близкраевое излучение пленок $\mathrm{ZnO}$, выращенных методом молекулярно-пучковой эпитаксии, в широких интервалах изменения интенсивности возбуждения (до $\left.1000 \mathrm{~kW} / \mathrm{cm}^{2}\right)$ и температур $(5-300 \mathrm{~K})$. Обсуждаются проявления экситон-фононного, экситон-экситонного и экситон-электронного взаимодействий в спектрах стимулированного излучения. Обнаружена смена механизмов стимулированного излучения в различных интервалах температур.

Ключевые слова: экситонное излучение, стимулированное излучение, экситон-экситонное взаимодействие, экситон-электронное взаимодействие.

DOI: 10.21883/FTT.2021.12.51678.175

\section{1. Введение}

$\mathrm{ZnO}$ является классическим объектом для изучения экситонных состояний. Подробно исследованы свободные, связанные, поверхностные экситоны в $\mathrm{ZnO}$ и их взаимодействие с фононами. Это соединение находит и широкое практическое использование: в солнечных батареях, медицинских маркерах, фотокатализаторах многих химических реакций, газоанализаторах, источниках интенсивного УФ-излучения и др. [1]. Высокая энергия связи в $\mathrm{ZnO}(60 \mathrm{meV})$ позволяет экситону принимать участие в ряде процессов при комнатной температуре.

При высоких уровнях возбуждения активно исследуются процессы экситон-экситонного взаимодействия: излучение свободных и связанных биэкситонов, излучение взаимодействующих экситонов, при котором часть энергии одного экситона передается другому с переходом последнего в возбужденное состояние или вызывая его ионизацию $(P$-процесс). При этом часть энергии экситона может передаваться и электрону (экситонэлектронное взаимодействие). На соответствующих полосах излучения при определенных условиях наблюдаются стимулированное излучение (СИ) и лазерная генерация (ЛГ). При этом пороги ЛГ при этих процессах ожидаются более низкими, чем для электронно-дырочной плазмы [2]. Впервые в ZnO ЛГ в микрокристаллах наблюдалась в 1989 г. [3].

В настоящей работе исследована природа СИ в пленке $\mathrm{ZnO}$ в широком температурном интервале. Обсуждаются механизмы стимулированного излучения. Предполагается, что при температурах от 5 до $120 \mathrm{~K}$ ответственными за СИ являются процессы экситон-фононного и экситон-экситонного взаимодействия, а в интервале
$120-300 \mathrm{~K}$ - процессы экситон-экситонного и экситонэлектронного взаимодействий.

\section{2. Методика}

Исследования ФЛ при $T=5-300 \mathrm{~K}$ проводились в гелиевом криостате замкнутого цикла фирмы „Janis Research Company“. Возбуждение ФЛ осуществлялось азотным лазером ЛГИ-505 в прямой геометрии. Длина волны возбуждения лазера составляла $337 \mathrm{~m}$ при частоте повторений $1 \mathrm{kHz}$ с длительностью импульса $7 \mathrm{~ns}$ и средней мощностью $105 \mathrm{~mW}$. Плотность возбуждения менялась в диапазоне от 4 до $1000 \mathrm{~kW} / \mathrm{cm}^{2}$.

Исследовалась пленка $\mathrm{ZnO}$ толщиной $d=420 \mathrm{~nm}$, выращенная методом молекулярно-пучковой эпитаксии (MBE) на сапфире без последующего отжига. Характеризация пленок осуществлялась методами рентгеновской дифракции (XRD) и электронной сканирующей микроскопии (SEM). Образец представлял собой пленку гексогональной структуры с ориентацией оптической оси $c$ по нормали к поверхности. Низкотемпературный спектр ФЛ, полученный при слабом возбуждении, свидетельствовал о высоком качестве образца.

\section{3. Результаты}

На рис. 1 показана эволюция спектров люминесценции (СЛ) пленки $\mathrm{ZnO}$ при увеличении мощности возбуждения при $T=5 \mathrm{~K}$. Кривая $1-$ минимальное возбуждение (спектр люминесценции совпадает со спектрами при возбуждении гелиево-кадмиевым лазером) кривые 2-7 - спектры фотолюминесценции (СФЛ) при возбуждении азотным лазером при увеличении мощности лазера $W$ от 3 до $1000 \mathrm{~kW} / \mathrm{cm}^{2}$. На кривой 1 


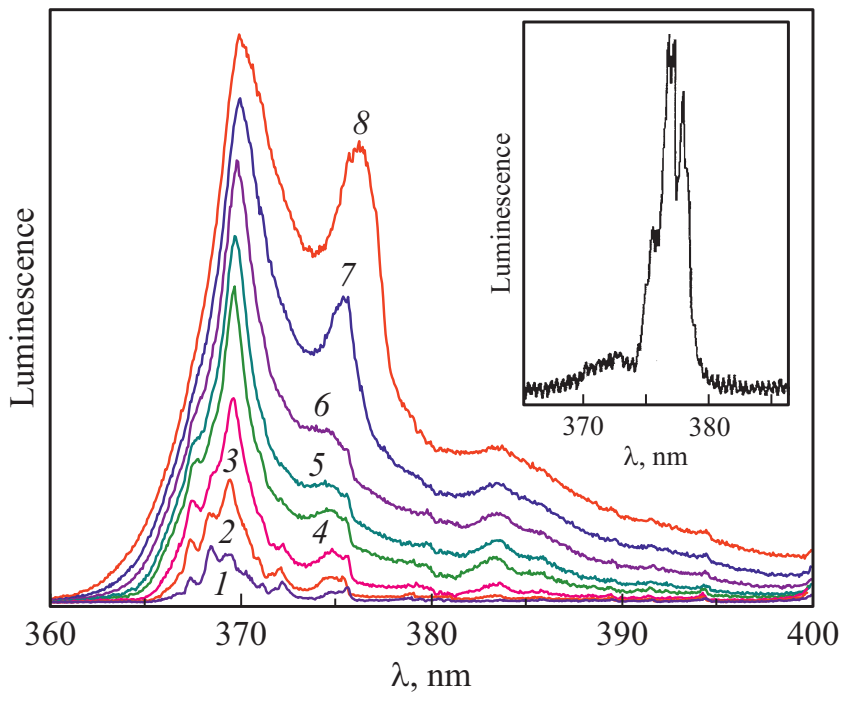

Рис. 1. Спектры ФЛ пленки $\mathrm{ZnO}$ при $T=5 \mathrm{~K}$ в зависимости от интенсивности возбуждения, увеличивающейся от 20 (кривая 1) до 1000 (кривая 8) kW/ $\mathrm{cm}^{2}$. На вставке - спектр лазерной генерации в области первого фононного повторения свободного экситона при $T=5 \mathrm{~K}$.

отчетливо проявляется известная из предыдущих исследований основная структура [4], характерная для СЛ $\mathrm{ZnO}$ при слабых возбуждениях - полосы излучения свободного экситона FX (367.7 nm), экситонов, связанных на донорных $D(X)$ и акцепторных $A(X)$ центрах, и полосы первого и второго фононного повторений (ФП) свободного экситона (376 и $383.5 \mathrm{~nm}$ соответственно), обычно слабые при $5 \mathrm{~K}$ в чистых образцах.

В области $375 \mathrm{~nm}$ видна полоса, максимум которой в литературе связывается с переходом экситон-акцептор, сюда же $(374.4 \mathrm{~nm})$ попадает и излучение экситонэкситонного взаимодействия ( $P$ - полоса). С увеличением возбуждения вид спектра меняется - линии связанных экситонов растут, перераспределяется их интенсивность, быстрее всех растет линия экситона, связанного на акцепторе $(369.1 \mathrm{~nm})$. Полоса свободного экситона уширяется (кривая 6), растет и начиная с $400 \mathrm{~kW} / \mathrm{cm}^{2}$ наблюдается как перегиб на коротковолновом крыле интенсивной полосы с максимумом при $369 \mathrm{~nm}$. Излучение на этой длине волны продолжает расти и тогда, когда все связанные экситоны уже не наблюдаются. Естественно предположить, что при увеличении возбуждения значительный вклад в излучение начинают вносить биэкситоны. В [5] в нанопленках $\mathrm{ZnO}$ было обнаружено излучение биэкситонов при $\lambda=369.1 \mathrm{~nm}$ и $W=200 \mathrm{~kW} / \mathrm{cm}^{2}$. С дальнейшим увеличением возбуждения полоса продолжает расти и уширяется, приобретая длинноволновый хвост. Положение максимума полосы (в дальнейшем обозначаемой как полоса $A$ ) при максимальном возбуждении - $370 \mathrm{~nm}$ (кривая 8).

Параллельно при увеличении интенсивности возбуждения быстро растет полоса стимулированного излуче- ния в области первого фононного повторения с максимумом при $\lambda=376.5 \mathrm{~nm}$ (далее полоса $B$ ). В сторону длинных волн от нее видна относительно слабая полоса второго фононного повторения. При дальнейшем увеличении возбуждения в спектральной области первого ФП возможно наблюдение лазерной генерации (см. вставку).

Из рис. 2 видно, что поведение интенсивностей полос $A$ и $B$ с ростом мощности возбуждения различно. В случае полосы $A$ (кривая 2) при высоких уровнях возбуждения наступает насыщение интенсивности, тогда как полоса $B$ (кривая 1 ) при $W>300 \mathrm{~kW} / \mathrm{cm}^{2}$ начинает резко расти.

На рис. 3 представлены СЛ-пленки при максимальном возбуждении в интервале температур 5-300 К. Обраща-

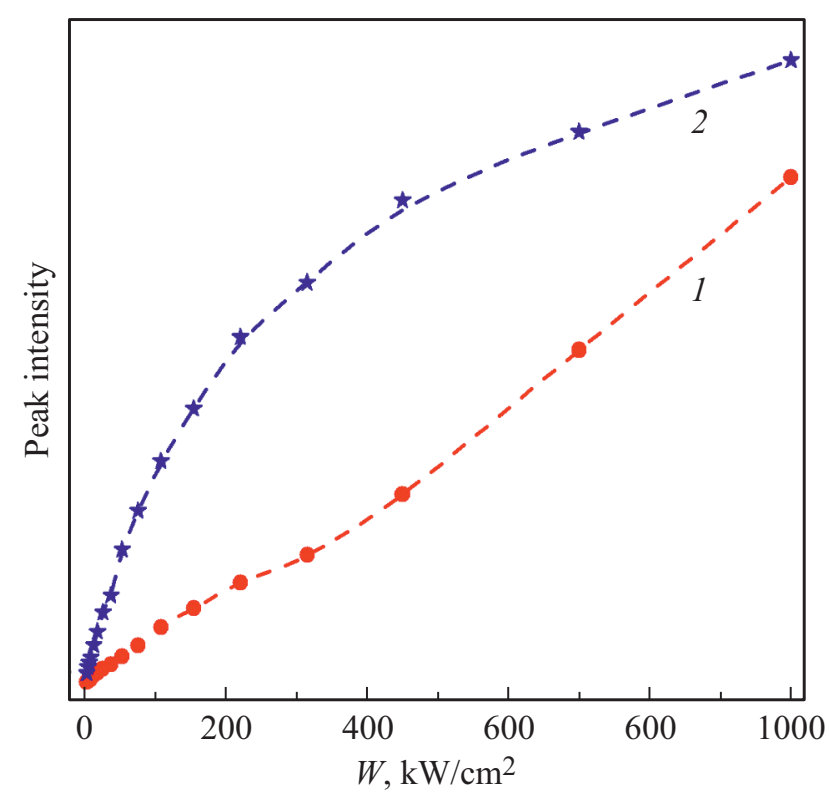

Рис. 2. Зависимости интенсивностей полос $B$ и $A$ (кривые 1 и 2 соответственно) от мощности возбуждения.

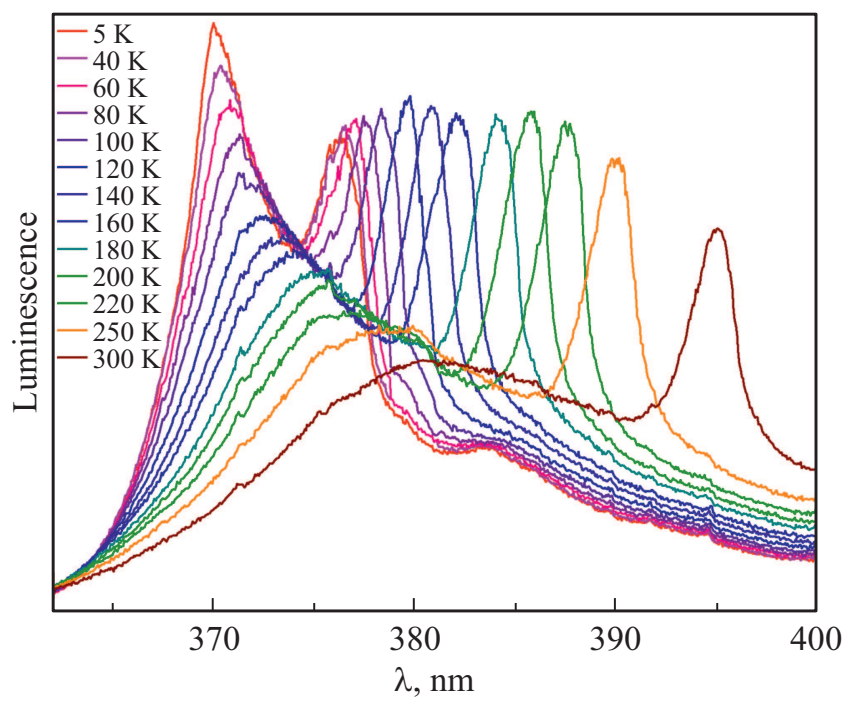

Рис. 3. Спектры ФЛ пленки $\mathrm{ZnO}$ в интервале температур $5-300 \mathrm{~K}$ при мощности возбуждения $W=1000 \mathrm{~kW} / \mathrm{cm}^{2}$. 


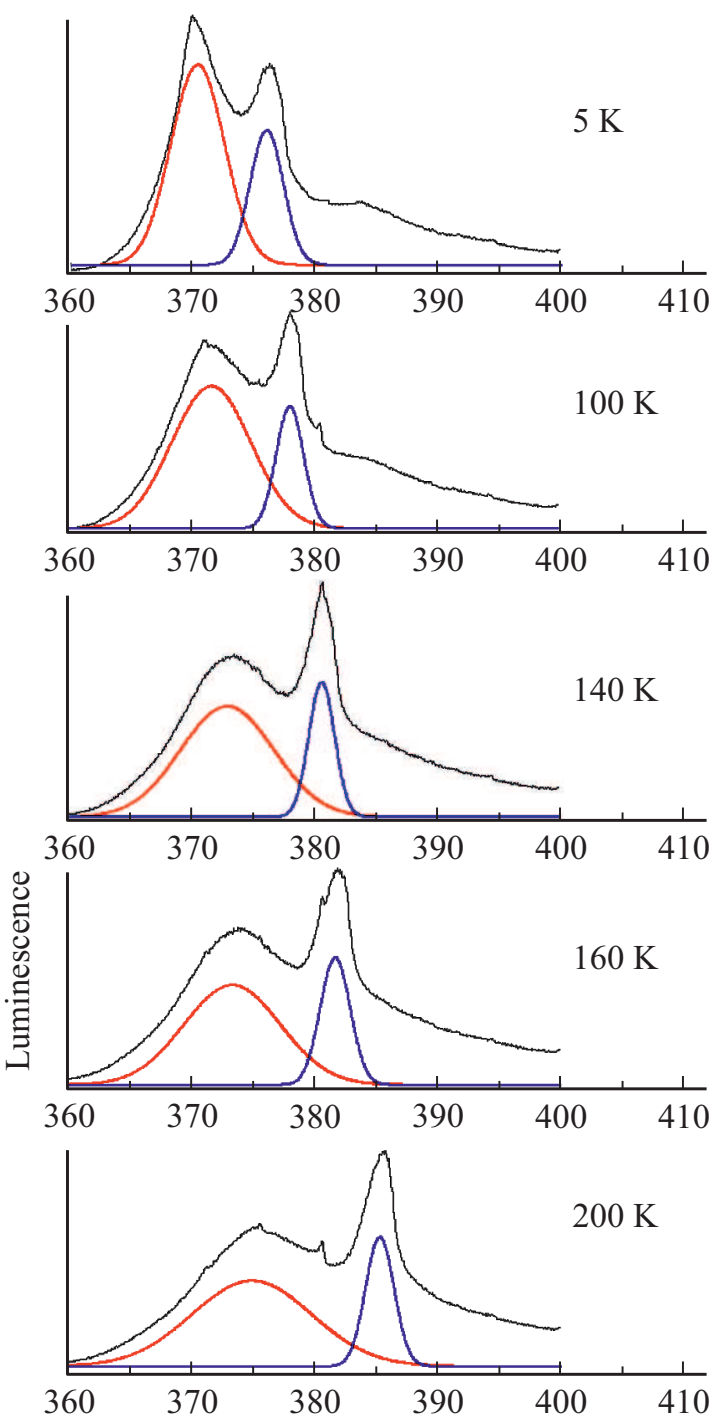

рокую полосу с максимумом при $382 \mathrm{~nm}$ [4]. Эволюция второй полосы излучения (полоса $B$ ) более сложная. Полоса $B$ смещается с температурой в длинноволновую сторону, однако ее полуширина остается практически неизменной во всем температурном интервале, а интенсивность слабо колеблется с повышением температуры: растет до $120 \mathrm{~K}$, а затем падает в интервале $160-300 \mathrm{~K}$. На рис. 4 дана картина разложения полос, представленных на рис. 3, более детально показывающая динамику температурного изменения люминесценции.

На рис. 5 представлена температурная зависимость максимумов полос излучения $A$ и $B$ (кривые 5 и 6 ) при максимальном возбуждении и известные из литературных данных температурные зависимости основных каналов экситонного излучения ФЛ $\mathrm{ZnO}$ (кривые $1-4$ по данным $[4,6])$.

Из рисунка видно, что кривая температурного изменения полосы $A$ (кривая 6 ) практически синхронна температурной зависимости $F X$. Динамика полосы $B$ (кривая 5) не совпадает ни с одной ранее изученной и интерпретированной полосой ФЛ, что подтверждает ее сложную природу. Можно выделить несколько температурных диапазонов, в которых изменение ее с температурой совпадает с различными каналами излучения. В температурном интервале $5-50 \mathrm{~K}$ ход температурной зависимости близок к зависимости первого фононного повторения свободного экситона. До $T=120 \mathrm{~K}$ полоса $B$ смещается практически идентично полосе $A$, однако при

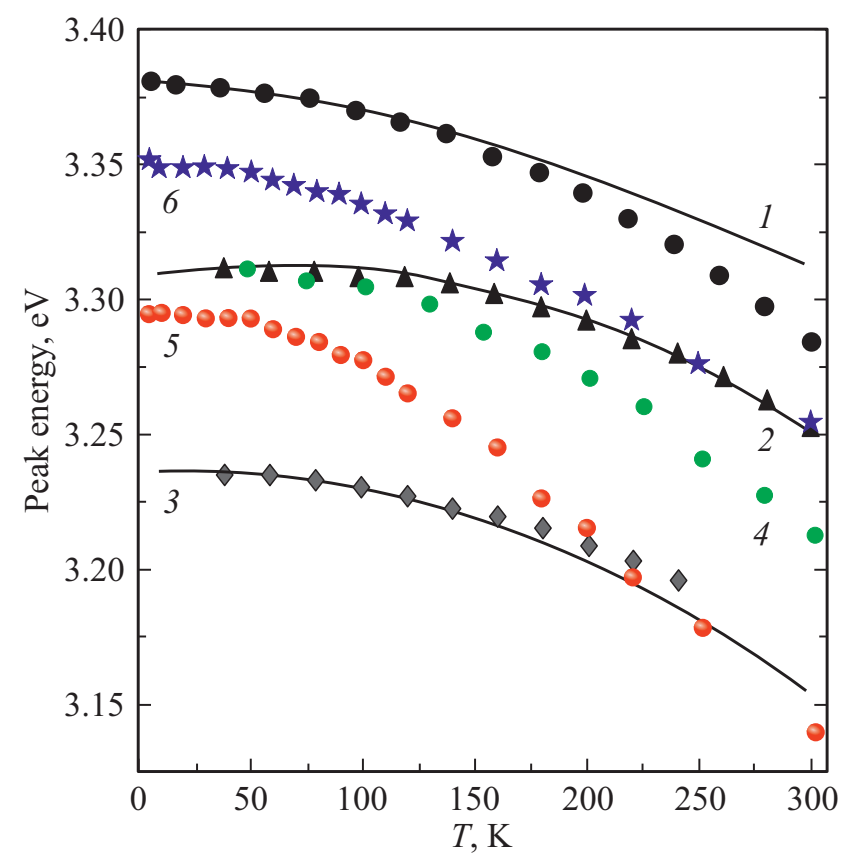

Рис. 5. Температурная зависимость максимумов полос люминесценции пленки $\mathrm{ZnO}: 1-4-$ литературные данные [6]: $1-F X, 2-1 L O(F X), 3-2 L O(F X) ; 4-$ экситон-экситонное взаимодействие по данным [4]; 5 - полоса $B, 6-$ полоса $A$ (экспериментальные результаты при $W=1000 \mathrm{~kW} / \mathrm{cm}^{2}$, настоящая работа). 
дальнейшем повышении температуры наклон кривой сильно увеличивается, что приводит к тому, что уже при $T=230 \mathrm{~K}$ она совпадает с ходом зависимости второго фононного повторения свободного экситона. Такой ход температурной зависимости полосы В предполагает различную природу СИ в разных диапазонах температур.

\section{4. Обсуждение результатов}

Из представленных результатов видно, что при увеличении мощности возбуждения линии связанных экситонов уширяются и увеличивается их интенсивность, но при этом не происходит их заметного смещения в длинноволновую сторону. Наиболее интенсивно возрастает линия с длиной волны $369.1 \mathrm{~nm}(3.36 \mathrm{eV})$. По нашим данным, она соответствует образованию биэкситона [5]. В дальнейшем эта полоса вместе с линиями свободного и связанных экситонов образует широкую полосу с длинноволновым хвостом и максимумом около $370 \mathrm{~nm}$, полуширина полосы - $48 \mathrm{meV}$. Можно предположить, что при сильных возбуждениях полоса состоит из частично ионизованных и экранированных экситонных состояний и электронно-дырочной плазмы. Как показали теоретические расчеты, при использованных мощностях возбуждения в $\mathrm{ZnO}$ возможно образование электроннодырочной плазмы [2,7].

При увеличении интенсивности возбуждения на длинноволновом спаде максимума возникает узкий пик СИ (полоса $B$ ). Стимулированное излучение в $\mathrm{ZnO}$ наблюдается в ряде работ (см. [2,8,9]). Интерпретация результатов затруднена тем, что в этой спектральной области находятся линии различной природы: $P$-полоса, фононное повторение свободного экситона $1 L O$, переход зона проводимости - акцептор.

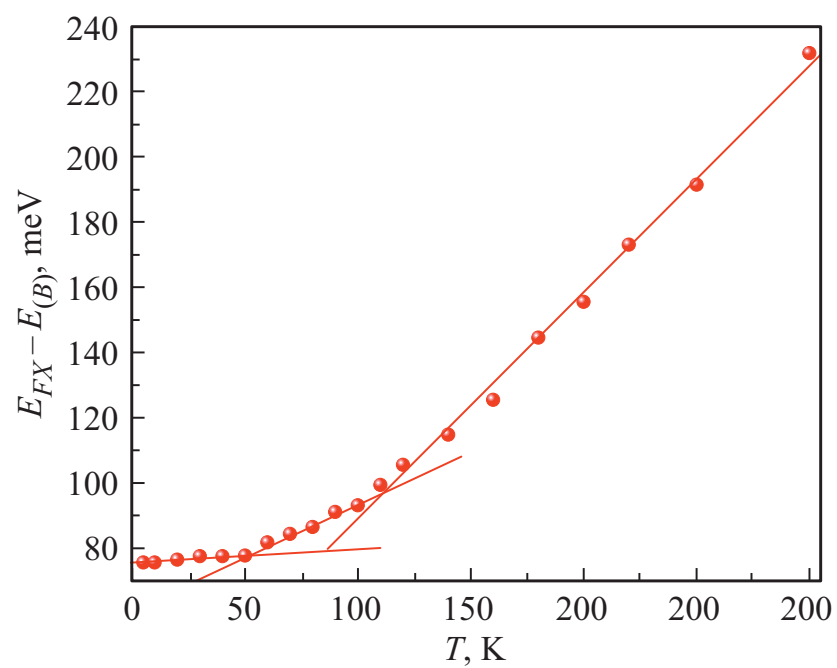

Рис. 6. Зависимость от температуры энергии $\Delta E$, где $\Delta E=E_{F X}-E_{(B)}-$ разность энергий свободного экситона и полосы СИ.
Из исследований температурной зависимости следует, что при $T=5 \mathrm{~K}$ СИ в наших образцах по спектральному положению близко к положению первого ФП свободного экситона. Однако температурные смещения этих полос существенно различаются. В интервале температур 220-240 K температурный ход СИ весьма точно совпадает с ходом фононого повторения экситона $2 L O$. Если принять, что СИ связано с отдачей фононов в решетку, то возникают трудности описания процесса в интервале температур 5-200 K и переходе от однофононного к двухфононному процессу. С другой стороны, при высокой интенсивности возбуждения возникает СИ экситон-экситонного и экситон-электронного взаимодействий. На рис. 6 показана температурная зависимость разности энергий свободного экситона и СИ. Можно выделить три температурных участка с различным наклоном, свидетельствующих в пользу существования различных механизмов СИ в этих температурных интервалах. Из рис. 6 видно, что разность энергий экситона и СИ слабо меняется в интервале температур 5-100 K, а при $T>100 \mathrm{~K}$ она резко увеличивается с ростом температуры. Можно предположить что имеет место $P$-процесс. Температурный ход полосы СИ аналогичен ходу полосы в работе [2], где предполагается $P$-процесс.

\section{5. Заключение}

В работе исследовано близкраевое излучение МВЕ пленок $\mathrm{ZnO}$ в широких интервалах изменения интенсивности возбуждения (до $1000 \mathrm{~kW} / \mathrm{cm}^{2}$ ) и температур $(5-300 \mathrm{~K})$. Обсуждается влияние экситон-фононного, экситон-экситонного и экситон-электронного взаимодействий на природу СИ. Показано, что при высоких температурах $(T>160 \mathrm{~K})$ преобладающими механизмами стимулированного излучения в $\mathrm{ZnO}$ являются экситонэкситонное и экситон-электронное взаимодействия.

\section{Финансирование работы}

Работа выполнена при поддержке грантами СПбГУ № 73031758 и № 72829385, № 19-72-30004.

\section{Конфликт интересов}

Авторы заявляют, что у них нет конфликта интересов.

\section{Список литературы}

[1] C. Klingshirn, J. Fallert, H. Zhou, J. Sartor, C. Thiele, F. MaierFlaig, D. Schneider, H. Kalt. Phys. Status Solidi B 6, 1424 (2010).

[2] R. Matsuzaki, H. Soma, K. Fukuoka, K. Kodama, A. Asahara, T. Suemoto, Y. Adachi, T. Uchino. Phys. Rev. B 96, 125306 (2017).

[3] В.А. Гайсин, Б.С. Кулинкин, Б.В. Новиков. Письма в ЖЭТФ 49, 11, 597 (1989). 
[4] И.Х. Акопян, М.Э. Лабзовская, Б.В. Новиков, А.Ю. Серов, Н.Г. Философов, Н.Р. Григорьева. ФТТ 62, 3, 1902 (2020).

[5] И.Х. Акопян, М.Э. Лабзовская, Б.В. Новиков, V.G. Talalaev, J.W. Tomm, J. Schilling. ФTT 61, 3, 533 (2019).

[6] U. Ozgur, Ya.I. Alivov, C. Liu, A. Teke, M.A. Reshchikov, S. Dogan, V. Avrutin, S.-J. Cho, H. Morkos. J. Appl. Phys. 98, 041301 (2005).

[7] Н.Н. Васильев, Е.Н. Борисов, Б.В. Новиков. ФТТ 62, 10 , 1607 (2020).

[8] C. Cachoncinlle, C. Hebert, J. Perrière, M. Nistor, A. Petit, E. Millon. Appl. Surf. Sci. 336, 103 (2015).

[9] J. Fallert, R.J.B. Dietz, M. Hauser, F. Stelzl, C. Klingshirn, H. Kalt. J. Lumin. 129, 1685 (2009).

Редактор Е.Ю. Флегонтова 